\title{
Several Thoughts on Current Chinese Education in the Philippines
}

\section{Shimin Yang}

\author{
Science and Technology College, Jiangxi Normal University, Nanchang, 330027, China
}

\author{
Keywords: Philippine language environment; Chinese
}

\begin{abstract}
There is an extremely long contact history between China and the Philippines. Although Philippine people are more and more interested in learning Chinese and the quality of Chinese education in the Philippines remains to be improved, the friction between Chinese and Philippine government, "Philippine" education system of Philippine government, and complicated multi-language environment are all reasons which results in not optimistic status of Chinese education. Those problems have seriously hindered the further development of Chinese education in the Philippines. Based on above problems, this paper proposes corresponding countermeasures for the purpose of promoting Chinese education to realize reasonable, rich, and occupational development.
\end{abstract}

\section{Introduction}

The non-governmental exchange between Chinese and Philippine people has a long history. In 1899, the 1st school for overseas Chinese - Da Qing Zhong Xi Xue Tang was established, which marked the beginning of Chinese education in the Philippines. After 1990s, with China's overall rapid rising and Chinese government's great support for popularizing overseas Chinese, the wave of learning Chinese sweeps across the global. This also causes great influence on Philippine Chinese education and also causes many new changes compared with previous Chinese education. Meanwhile, some new problems which hinder the development of Chinese education also appear.

\section{Current situation of Chinese education in the Philippines}

Currently, there are 207 elementary and secondary schools for overseas Chinese, 3 state-run Confucius institutes, and 27 colleges with Chinese course set in Manila region. [2] Most of students in the elementary and secondary schools for overseas Chinese are overseas Chinese students, and only few non-Chinese students. However, the colleges consists of overseas Chinese students and non-Chinese students, and the latter accounts for a major proportion.

(I) Property of Chinese teaching for non-Chinese students

While studying for a PHD, the author has mainly investigated and knew Chinese teaching situation in 5 colleges, including University of the Philippines, Ateneo de Manila University, De La Salle University, University of the East, and Philippine Normal University. The age of students varies from 16 to 38, and the students are basically Philippine Malay people. The non-Chinese students didn't contact Chinese in the past, and all of them have zero foundation. Currently, there are only few students who professionally engage in learning Chinese in those colleges, and most courses are electives. According to the rules of class hours of Philippine higher education committee, the teaching hours of Chinese are 6 class hours per week; the learning time is little, and the forgetting rate is high, thus Chinese teachers shall at least spend 10 minutes to review the content learnt in last lesson in each lesson. Due to lack of Chinese practice chance and large social environment in the Philippines and advocating for American education, the students pay insufficient attention to Chinese characters after class, and the phenomenon that the students can speak Chinese but can't write Chinese characters often appears.

(II) Lack of language environment, and bad teaching effect

The language environment is an important factor which improves oral Chinese ability. There are almost one million Chinese people who are born and grow up in the Philippines; if the people with Chinese origin are included, the quantity can be almost ten million [3]. However, it is a pity that 
young Chinese people are losing Chinese language environment despite of large number of Chinese people. There are following reasons: 1 . Chinese people commonly have good economic foundation in the Philippines, and most of families employ Filipino domestic workers to bring up their children; however, due to low wage, local Filipino domestic workers are basically rural women with low education level; they have poor oral English and commonly communicate with people in Tagalog; because the children are brought up by Filipino domestic workers, the Filipino becomes children's first language. 2. After the second generation of Chinese people in the Philippines get married with non-Chinese people, those families generally use English or Tagalog as mother tongue for communication, for the Chinese can't be used in parents' daily communication. 3. Due to unequal treatment on schools for overseas Chinese in the Philippines, most of parents hope that their children can blend in Philippine society and select to let their children study in Philippine conventional schools or international schools; in this way, they lose the chance of practicing Chinese again. Under the restriction of those factors, many young Chinese people can't or are unwilling to use Chinese as communication language, and the Chinese language environment is gradually losing.

(III) Insufficient school-running resources, and weak faculty power

The school funding for Chinese schools in the Philippines mainly depends on the income from students' tuition and the donation from Philippine Chamber of Commerce. The Philippine government almost gives no fiscal subsidies and preferential policies on Chinese schools, and the social status of Chinese schools in the Philippines have all their goods in the window. Same as other Southeast Asian countries, the Philippines also faces the problem of insufficient fund and faculty in terms of Chinese education. Currently, the Chinese teachers in Philippine Chinese schools mainly consist of teachers and volunteers selected and detached by Chinese Language Council, Chinese teachers selected from Taiwan Overseas Chinese Affairs Council, and local Chinese teachers in the Philippines. Except for insufficient faculty, there also exist some problems such as low quality, low professional degree, unbalanced gender ratio, and instable teaching staff in Chinese teachers. The shortage of high-quality faculty and unreasonable entire composition has become one of the most serious problems that Philippine Chinese education faces. [4] Besides, after 2011, the diplomatic relation between China and the Philippines is always tight; in the beginning of 2014, the diplomatic relation is up to freezing point, which results in serious shortage of Chinese teachers in partial Chinese schools. Finally, under the active coordination of Philippine Chamber of Commerce, the employment crisis is solved through faculty sharing of Chinese schools and employment of Chinese overseas students in the Philippines. Although the crisis is solved, the new problems also appear. Many newly-employed Chinese overseas students in the Philippines are employed as Chinese teachers only due to their Chinese skills, and they have not accepted professional training; meanwhile, because those students need to learn their own profession courses, it is very difficult for them to spend great energy and time in researching teaching method and improving teaching quality. Furthermore, "the rarer a thing is, the more it is worth"; the Chinese teachers lack of competition, which causes low occupational barrier and no pressure on Chinese teachers, thus the teaching staff have low educational level and the professional Chinese talents are insufficient.

(IV) Non-uniform teaching materials and old-fashioned teaching method

The teaching effect assessment is a comprehensive assessment system, and it is closely related with teaching materials, teaching way, and students. Currently, the teaching materials used in Philippine Chinese schools are diversified, and they mainly come from free books provided by Chinese Mainland government and Taiwan Province, as well as charged books from Philippine Chinese Education Research Center, and few schools introduce relevant Chinese teaching materials from Singapore and Malaysia. Due to subjective selection of founders and sponsors of Chinese schools, there also commonly exist following situations in Chinese characters in teaching of Philippine Chinese schools: partial schools use traditional Chinese character teaching materials, partial schools use simplified Chinese character teaching materials, and partial schools use combined teaching of traditional and simplified Chinese characters. This mixed phenomenon not only increases students' difficulty in learning Chinese, but also results in difficulty in realizing 
uniform teaching quality assessment on Chinese courses, which is disadvantageous for testing teaching effect and balancing advantages and disadvantages of Chinese schools.

However, in terms of teaching way, due to complex structure of Chinese teaching staff, the teachers' teaching way, teaching level, and teaching effect are all different. Some high-level teachers with rich experience can quickly bring students into Chinese world and realize quick growth of students' Chinese level. However, as for some teachers with insufficient teaching experience, due to lack of professional training of language teaching, they still use traditional teaching way in Chinese Mainland and regard overseas Chinese students in the Philippines as Chinese mother-tongue students for teaching, thus resulting in the situation that the teachers talk too much, but the students practice little; the teaching is dull, and the learning and practice is detached; there is more mechanical memorizing than flexible use. The phenomenon of "dumb Chinese" becomes a new difficulty which perplex Chinese educators.

\section{Suggestions on countermeasures of improving Chinese schooling level}

The Chinese education has existed in the Philippines for hundreds of years, but it still has many deficiencies. In order to better popularize and inherit Chinese culture, the Chinese education must face the adversity and seek for countermeasures and strategies to effectively solve the outstanding problems which hinder the development. The Chinese reform is imperative.

(I) To strive for policy support and expand fund investment

In order to obtain breakthrough development in the Philippines, the Chinese education must obtain many aspects of support from Philippine government. In recent years, the Philippine government also has realized the importance of Chinese, and has gradually relaxed the policy of Chinese education. However, the author thinks that the support is still insufficient, and the Chinese people in the Philippines of all circles shall unite together to seek for more support from Philippine government. 1. Invite the government to participate in management, development, and reform of Chinese schools, and provide certain subsidy and fund to alleviate the schooling pressure of Chinese schools and make Chinese schools truly become an important member of Philippine national education system. 2. Seek for the support from Chinese Mainland and Taiwan on Chinese education; except for keeping original support projects, make full use of provided resources to improve hardware facilities of Chinese teaching and promote the popularization of Chinese education in mainstream society and mainstream schools. 3. Borrow ideas from successful experience of The United Chinese School Teachers' Association Of Malaysia and United Chinese School Committees'Association of Malaysia in seeking for equal status for Chinese popularization and construction of Chinese schools in Malaysia. Philippine Chamber of Commerce and Philippine Chinese Education Research Center take the lead to organize Chinese popularization and right protection association belonging to Chinese people in the Philippines so as to seek for more fair treatment and equal development opportunities for Chinese schools. 4. Expand fund investment. The Chinese schools in the Philippines are basically privately funded and established, and most of Chinese schools depend on students' tuition and limited social denotation to make a simple living; the most direct and effective method to change the current situation of poor equipments and poor teaching in Chinese schools is to expand construction investment. The Chinese people in the Philippines can borrow Malaysia's successful experience and realize improvement via three steps: uniting all Chinese people in the Philippines, encouraging the free airing of views, and encouraging the donation from Chinese people, Philippine associations, and chambers of commerce; utilizing the social status of Chinese people in the Philippines to seek for economic investment of Philippine government; uniting the support from all overseas Chinese associations and foundations. Those methods are used to seek for more available capital for Chinese schools as much as possible.

(II) To enhance construction of Confucius Institute, and cultivate local Chinese teaching staff

To solve "teacher shortage" problem shall be one of effective means for Philippine Chinese schools to improve schooling level. Although Philippine government has officially launched volunteer Chinese teacher teaching action since 2003 and the shortage of Chinese teaching staff is mitigated to some degree, those Chinese volunteer teachers only have 1-2 years of teaching time in 
the Philippines, thus it is unable to keep the consistency of Chinese teaching. Therefore, the teacher shortage problem can be truly solved only via cultivating local Chinese teachers; in this way, it is able to have an effective and stable teaching staff.

In 2006, the Philippines established the 1st Confucius Institute -- Ateneo de Manila University Confucius Institute, and then it established Bulacan State University Confucius Institute and Confucius Institute at Angeles University Foundation; these three universities all enjoy high popularity in the Philippines. We shall regard these three universities as the basis to cultivate high-education background and high-quality local Chinese teachers. Firstly, Chinese Language Council shall expand the investment on these three Confucius institutes and provide sufficient policy and fund as well as sufficient number of detached Chinese teachers. Secondly, it is required to encourage more Philippine students to apply for Chinese major or Chinese elective course; through tuition waiver, scholarship, and preferential policy for international students studying in China, it is able to attract more high-quality students. Thirdly, with reference to the successful mode of "Chinese language 2+2" teacher class established under cooperation between Philippine Chinese school Chiang Kai Shek College and Fujian Normal University in order to solve the problem of shortage of Chinese teachers of Chinese schools, we can further expand the opportunities for Philippine excellent Chinese students to study in China, and make use of Confucius institute platform and excellent teaching and Chinese environment of Chinese domestic universities to let Philippine students learn Chinese, know Chinese, and utilize Chinese in a better way so as to lay a firm foundation for better spreading of Chinese culture and Chinese language in the future.

(III) To uniformly compile teaching materials and optimize teaching mode

Currently, Chinese government shall compile targeted teaching materials together with Philippine Chamber of Commerce and Philippine Chinese Education Center to formulate a set of uniform teaching materials which adapt to time development and Philippine national conditions for Philippine students so as to be good for popularization of Philippine Chinese education reform results and business training of Chinese teachers.

Accurately positions Philippine "Chinese teaching” as "specific second language teaching which takes cultivating Chinese teenager's Chinese communication ability as basis and enriching their Chinese culture as purpose". Therefore, in terms of teaching mode, we shall focus on verbal communication skill training and verbal skill training, insist on essential teaching and multi-practice, and pay attention to listening, speaking, reading, and writing so as to realize harmonious development between students' oral expression ability and written expression ability; meanwhile, the attention shall be paid to exerting students' initiative and creativity, enhancing Chinese learning environment, expanding language input and output, and improving Chinese learning efficiency. It is believed that the Chinese teaching method will be reformed and optimized through joint efforts of Chinese educators in the Philippines.

(IV) To increase teacher employment threshold, and establish teacher assessment system

Currently, Philippine Chinese teachers have a low treatment, and the dissatisfaction with treatment is a major reason which results in large mobility of Chinese teachers. Therefore, in order to ensure a stable high-quality teaching staff, we shall firstly improve Chinese teachers' wage and social insurance treatment. Secondly, we shall implement teaching qualification system, and the teachers who pass the examination and obtain teacher certification can take the post. The specific practice can make reference. Thirdly, we can establish teaching assessment system to carry out monitoring and assessment on classroom teaching and learning through students' evaluation of teaching, teachers' evaluation of teaching, peer's mutual evaluation, and teachers' self-assessment. Fourthly, we can establish a perfect Chinese teacher professional title appraisal system. The appraisal result of professional title is not only directly related to wage, but also related to various scientific research project expenditure, further education, abroad exchange and other opportunities to form a virtuous circle development in which the teaching and scientific research drives professional title appraisal and the professional title appraisal improves the level of teaching and scientific research. 


\section{Conclusion}

The Philippines is a country of islands, and also a multinational country with open mind. Through a general survey of about 100-year development process of Philippine Chinese education, although there is fluctuation, the Chinese education still keeps forward under the joint efforts of Philippine Chinese people and Philippine Chinese associations. It is certain that there still exist different problems in construction of Chinese schools; however, with comprehensive implementation of Chinese education reform, it is believed that all problems will be solved in practice and development process. In a world, the Philippine Chinese education has a good development prospect.

\section{References}

[1] Shao Jianyin: Past, Present and Future of Chinese Education in the Philippines, [J], Taiwan: Chinese World (issue 72 of Taiwan Southeast Asian Chinese Education magazine), 1994, 81.

[2] Liao Xinling: Research on Development Status and Trend of Chinese Education in Southeast Asia [J], Overseas Chinese Journal of Bagui, 2009 (1), 55.

[3] Baibu Baike, Phippine Chinese http://baike.baidu.com/view/490873.htm?fr=aladdin

[4] Luo Qingming: Reference Problems in Philippine Chinese Teaching [J], Overseas Chinese Journal of Bagui, 1996 (3), 48-52. 